\title{
Visual evoked potential latency and contrast sensitivity in patients with posterior chamber intraocular lens implants
}

\author{
J W HOWE,' K W MITCHELL, ${ }^{2}$ M MAHABALESWARA, \\ AND M N ABDEL-KHALEK
}

From the 'University Department of Ophthalmology and the ${ }^{2}$ Regional Department of Medical Physics, Royal Victoria Infirmary, Newcastle upon Tyne NE1 4LP

SUMmARY An electrophysiological investigation of visual evoked potential (VEP) latency and contrast sensitivity was performed in a group of 13 patients who had undergone extracapsular cataract surgery with posterior chamber lens implantation. In spite of good postoperative visual acuity, abnormalities were detected in nine of the group (69\%). This study suggests that, even with successfully implanted lenses, there may be a reduction in visual function which could be the result of altered transmission through the plastic lenticulus or fibrosis of the posterior lens capsule, and/or subtle changes in retinal architecture, not observed ophthalmoscopically.

The optical disadvantages of spectacle lenses in the correction of aphakia make intraocular lenses (IOLs) an attractive alternative. Although intraoperative and postoperative complications have been widely reported, improvements in both lens design and surgical technique have reduced these problems, so that lens implantation is increasingly widely practised. In the USA alone it has been estimated that the implantation rate exceeds 500000 annually, ${ }^{\prime}$ and that posterior chamber lenses account for nearly two-thirds of these, the remainder largely comprising anterior chamber implants. There is also an increasing trend towards using IOLs in the UK, a recent survey suggesting that $45 \%$ of cataract operations involved the use of lens implants. ${ }^{2}$

The success of an implanted lens can be judged on the basis of low complication rate and by assessment of eventual visual acuity. On the basis of an acuity of $6 / 12$ or better a success rate of over $90 \%$ has been reported with posterior chamber implants ${ }^{3-5}$ and $87 \%$ in patients who have undergone intracapsular lens extraction with insertion of an anterior chamber implant. ${ }^{6}$ Visual acuity may, however, be normal in the presence of a variety of disorders in which overall contrast sensitivity is reduced.' This is the type of visual impairment in which some patients report 'fogginess' or 'haziness' of vision despite achieving

Correspondence to $\mathrm{Mr} \mathrm{J}$ W Howe. normal standards of visual acuity. In a recent report Hess et al. ${ }^{8}$ have detected abnormalities in contrast sensitivity, measured psychophysically, in patients with iris clip lenses inserted after intracapsular cataract extraction. As an alternative to psychophysical means, contrast sensitivity function can be estimated electrophysiologically by recording visual evoked potentials (VEPs). ${ }^{9}$ These are known to be influenced not only by retinal and optic nerve pathology but also by factors affecting the quality of the visual image on the retina, such as opacities of the media, refraction, and pupil size (for review, see Halliday $\left.{ }^{10}\right)$. On theoretical grounds alone it would appear that abnormalities in the VEP are likely to be seen in patients with IOLs.

We believe there have been no reports so far on electrophysiological changes in patients who have undergone intraocular lens implantation. We report here the results of a bimodal approach which has determined VEP latency and contrast sensitivity in 13 patients with good visual acuity following extracapsular surgery and posterior chamber IOL insertion.

\section{Patients and methods}

PATIENTS

Thirteen patients (age 57-70 years, mean 65.4 years) who had undergone successful extracapsular 
cataract extraction with insertion of a posterior chamber IOL were examined (Table 1). Each had a corrected visual acuity of $6 / 12$ or better in the pesudophakic eye, with no clinical evidence of retinal or optic nerve pathology and a normal intraocular pressure $(21 \mathrm{mmHg}$ or less). In 10 of these patients there was a variable degree of cataract in the contralateral eye, but in the remaining three the cataract had been unilateral and the visual acuity in the fellow eye $6 / 6$ or better. Results from these patients were compared with a normal, age matched population from our database (mean age 62.6, SD 9.3, $\mathrm{n}=55$ ).

\section{ELECTROPHYSIOLOGY}

A checkerboard stimulus was produced by a video pattern generator on a high quality TV monitor. In the first part of the test luminance modulation of the

(a)
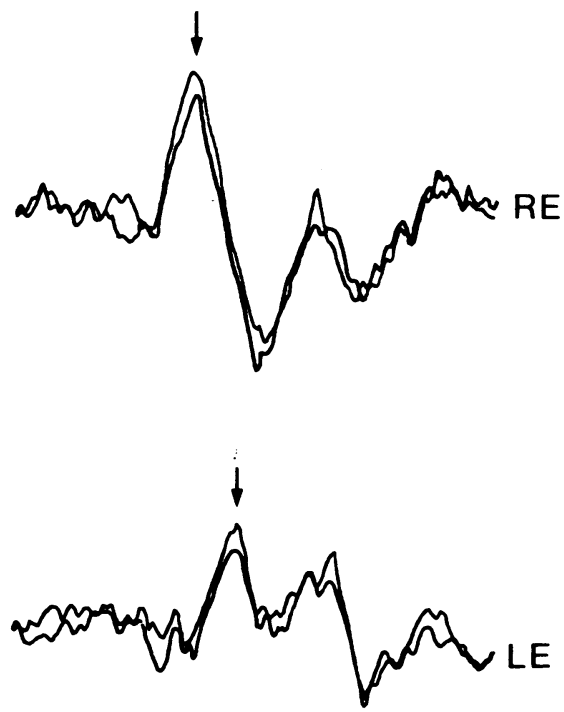

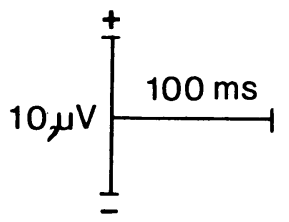

pattern was selected to give the pattern reversal mode of stimulation. The checksize of the stimulus was $50^{\prime}$ and the visual field subtended, $17^{\circ} \times 14^{\circ}$. The overall luminance of the TV screen - both with and without pattern-was maintained constant at $10 \mathrm{Cd}$ $\mathrm{m}^{-2}$. Pattern contrast (defined as $\left(\mathrm{L}_{\max }-\mathrm{L}_{\min }\right) /$ $\left(\mathrm{L}_{\max }+\mathrm{L}_{\min }\right)$ where $\mathrm{L}_{\max }$ and $\mathrm{L}_{\text {min }}$ were the luminance of the bright and dark checks respectively) was adjusted to be $95 \%$ with a reversal rate of 2 per second.

The second part of the test, to measure contrast sensitivity, was performed with the onset-offset mode of stimulation. The rationale for the selection of this type of pattern modulation is fully discussed elsewhere. ${ }^{9}$ The pattern was present for $40 \mathrm{~ms}$ every $500 \mathrm{~ms}$ (note: the presentation rate-as with pattern reversal mode-was locked to the $50 \mathrm{~Hz}$ monitor frame rate). Using a check size of $19^{\prime}$ for patients with

(b)
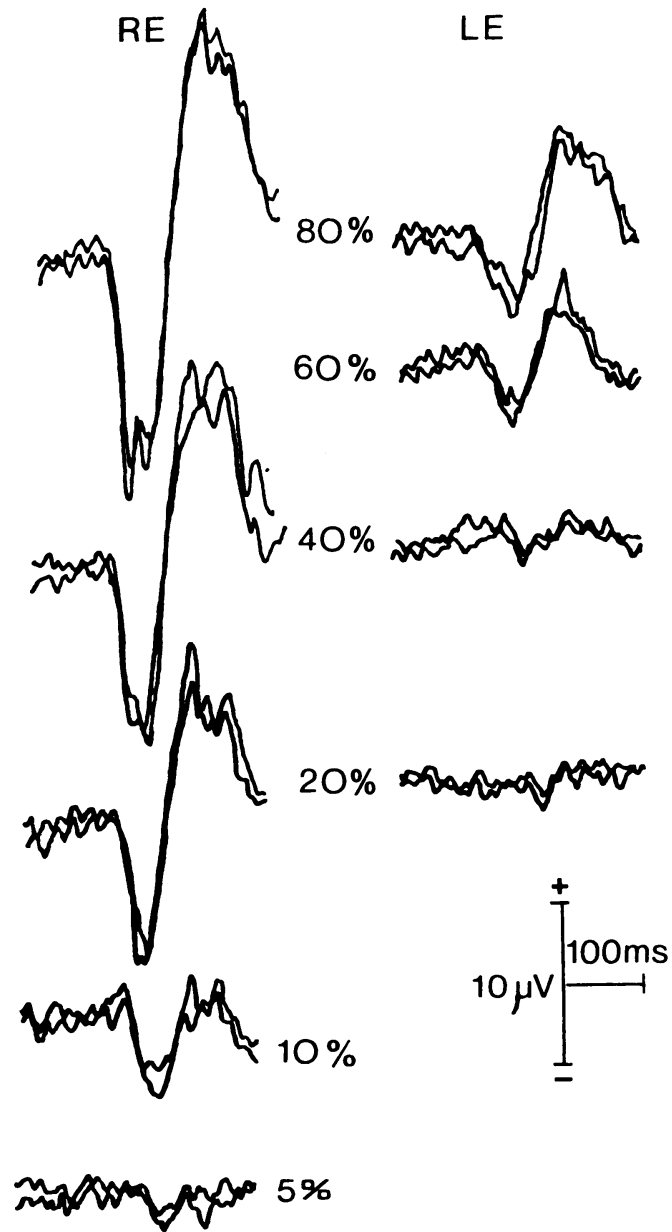

Fig. 1 VEPs from patient No. 7(LE pseudophakic RE normal). Pattern reversal responses are shown in column (a) and onset-offset responses at different contrast levels in column (b). 
a VA of $6 / 9$ or better and $25^{\prime}$ for those with an acuity of $6 / 12$, we made recordings at (usually) five contrast levels between $5 \%$ and $80 \%$. These were selected in a pseudorandom sequence to try to eliminate any possible order effects. The patients were given short periods of rest between each contrast measurement so as to minimise fatigue and any concomitant increase in response variability.

Silver/silver chloride disc electrodes were attached to the scalp with collodion, in the following positions: active-Oz; reference- $\mathrm{Cz}$; earth $-\mathrm{Pz}$.

A Medelec electrophysiological recording unit was used to amplify, average, and store the evoked potentials. The amplifier bandwidth was $0 \cdot 8-80 \mathrm{~Hz}$, and either 64 or 128 epochs of 300 ms duration were averaged depending on the size of the response. Two averages were obtained at each contrast level to check for consistency, and quantitative analysis was performed on the average of these two. A peak-peak amplitude measure was adopted: in the case of the pattern reversal VEPs it was that between P100 and $\mathrm{N} 150$, in those to onset-offset it was between components $\mathrm{CI}$ and CII. A permanent record of the responses was made on an X-Y plotter. Amplitude data from the traces were then fed into a MINC PDP-11 computer for storage and further analysis. Monocular stimulation was adopted in all investigations, the subject being instructed to maintain fixation and focus on a small LED marker attached to the centre of the screen. This was checked during the investigation by closed circuit TV monitoring. Before the start of the test the subject was preadapted to the luminance of the blank screen for 5 minutes. This was the only source of illumination in an otherwise darkened room. The test was concluded with the measurement of the subject's pupils under experimental conditions.

\section{Results}

In Fig. 1 the responses from a patient with a left intraocular implant and visual acuities of $6 / 6$ in each eye are illustrated. The pattern reversal responses indicated a delay in the main P100 component in the pseudophakic eye as compared with the RE. The onset-offset responses clearly showed reduced amplitude at all contrast levels in the LE. When the amplitude of these responses was plotted against log contrast (Fig. 2), significant differences between the two eyes were observed, not only in amplitude but also in the electrophysiologically estimated contrast threshold (arrowed).

In Table 1 data concerning all 13 patients in the study are presented. P100 latency was significantly increased (at the $1 \%$ confidence level) in four of the group, and increased contrast threshold in eight. It is

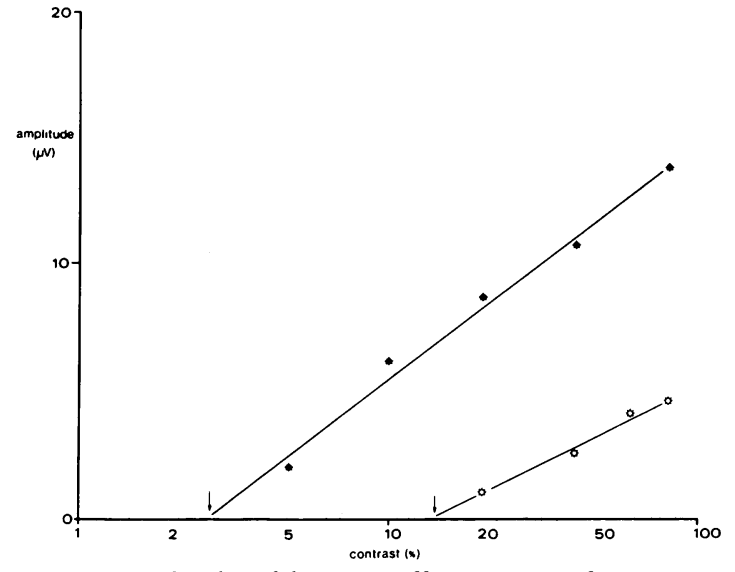

Fig. 2 Amplitudes of the onset-offset responses from patient No. 7. (Fig. 1) plotted against log-contrast. Closed symbols $(O)=$ normal $R E$. Open symbols $(O)=$ pseudophakic $L E$.

of interest that three of the four patients showing abnormal latency also had abnormal contrast thresholds. In addition, and perhaps of greater interest, is the fact that four patients with normal latencies showed elevated thresholds. In the group as a whole nine of the 13 patients showed some electrophysiological abnormality.

Table 2 shows the data concerning the three patients in whom it was possible to perform interocular comparisons, as the contralateral eye was normal. Interocular difference in latency was significant in two of the three patients (though the third was only marginally outside the $1 \%$ confidence level), and all three showed greater latencies in the pseudophakic eye. Interocular threshold differences were

Table 1 Visual acuity, VEP latency, and contrast threshold in pseudophakic eyes

\begin{tabular}{rlllc}
\hline Serialno. & Age & $V A$ & $\begin{array}{l}\text { P100 Latency } \\
(\mathrm{ms})\end{array}$ & $\begin{array}{l}\text { Contrast } \\
\text { threshold (\%) }\end{array}$ \\
\hline 1 & $60(\mathrm{M})$ & $6 / 6$ & $134 \cdot 0^{*}$ & $3 \cdot 3$ \\
2 & $61(\mathrm{M})$ & $6 / 9$ & $115 \cdot 0$ & $5 \cdot 0$ \\
3 & $69(\mathrm{M})$ & $6 / 6$ & $122 \cdot 0$ & $15 \cdot 0^{*}$ \\
4 & $64(\mathrm{~F})$ & $6 / 6$ & $125 \cdot 0$ & $3 \cdot 9^{*}$ \\
5 & $57(\mathrm{~F})$ & $6 / 9$ & $114 \cdot 0$ & $7 \cdot 7^{*}$ \\
6 & $70(\mathrm{M})$ & $6 / 12$ & $102 \cdot 0$ & $10 \cdot 9^{*}$ \\
7 & $65(\mathrm{~F})$ & $6 / 6$ & $138.0^{*}$ & $13 \cdot 8^{*}$ \\
8 & $66(\mathrm{~F})$ & $6 / 6$ & $113 \cdot 0$ & $8 \cdot 6^{*}$ \\
9 & $70(\mathrm{~F})$ & $6 / 9$ & $111 \cdot 0$ & $4 \cdot 6^{*}$ \\
10 & $61(\mathrm{M})$ & $6 / 9$ & $132 \cdot 0^{*}$ & $5 \cdot 2^{*}$ \\
11 & $68(\mathrm{M})$ & $6 / 6$ & $110 \cdot 0$ & $3 \cdot 9^{*}$ \\
12 & $69(\mathrm{M})$ & $6 / 12$ & $129 \cdot 0^{*}$ & $11 \cdot 9^{*}$ \\
13 & $70(\mathrm{M})$ & $6 / 6$ & $105 \cdot 0$ & $6 \cdot 1^{*}$ \\
\hline
\end{tabular}

* Significant at $1 \%$ level.

Normal P100 latency $=113.0$ (SD 6.2) $\mathrm{ms}(99 \% \mathrm{CL}=128.0 \mathrm{~ms})$

$(\mathrm{n}=55)$. Normal contrast threshold $=2 \cdot 1$ (SD $1 \cdot 3) \%(99 \%$

$\mathrm{CL}=5 \cdot 1 \%)(\mathrm{n}=49)$. 
Table 2 Interocular comparison in those patients with pseudophakia and a normal contralateral eye

\begin{tabular}{|c|c|c|c|c|c|c|c|c|c|c|}
\hline \multirow{2}{*}{$\begin{array}{l}\text { Serial } \\
\text { no. }\end{array}$} & \multicolumn{2}{|l|}{$V A$} & \multicolumn{2}{|l|}{ Diagnosis } & \multicolumn{3}{|c|}{ P100 Latency (ms) } & \multicolumn{3}{|c|}{ Contrast Threshold (\%) } \\
\hline & $R E$ & $L E$ & $R E$ & $L E$ & $R E$ & $L E$ & $(\Delta l)$ & $R E$ & $L E$ & $(\Delta t)$ \\
\hline 3 & $6 / 9$ & $6 / 6$ & Normal & Pseudophakia & $116 \cdot 0$ & $122 \cdot 0$ & $(6 \cdot 0)$ & $3 \cdot 2$ & $15 \cdot 1$ & $(11.9)^{*}$ \\
\hline 7 & $6 / 6$ & $6 / 6$ & Normal & Pseudophakia & $112 \cdot 0$ & $138 \cdot 0$ & $(26 \cdot 0)^{*}$ & $2 \cdot 8$ & $13 \cdot 8$ & $(11 \cdot 0)^{*}$ \\
\hline 10 & $6 / 9$ & $6 / 5$ & Pseudophakia & Normal & $132 \cdot 0$ & $125 \cdot 0$ & $(7 \cdot 0)^{*}$ & $5 \cdot 2$ & $2 \cdot 4$ & $(2 \cdot 8)^{*}$ \\
\hline
\end{tabular}

*Significant at $1 \%$ level.

Normal interocular latency difference $\Delta 1=2 \cdot 0$ (SD 1.9) $\mathrm{ms}(99 \% \mathrm{CL}=6 \cdot 3 \mathrm{~ms})(\mathrm{n}=55)$.

Normal interocular threshold difference $\Delta t=0 \cdot 8($ SD $0 \cdot 8) \%(99 \% C L=2 \cdot 7 \%)(n=49)$.

significant in all three patients, and again higher values were observed in the operated eye.

\section{Discussion}

Before it is possible to attach pathological significance to a delayed and/or attenuated VEP or depressed contrast sensitivity (that is, increased threshold) several confounding causes must be eliminated. To this end special attention was given to the selection of patients with good central acuity and no evidence of any retinal or optic nerve disorder as judged by careful ophthalmoscopy, perimetry, and fluorescein angiography. In all patients the corneae were clear on slit-lamp examination, and no significant vitreous opacities were observed. The posterior capsule was intact in all patients. The size of the pupil can also be a source of error, as miosis reduces retinal illumination, which in turn increases VEP latency. Pupillary diameter was directly measured and was not significantly different from the normal range; it was never less than $3 \mathrm{~mm}$ in any of the eyes investigated, thus being excluded as a possible causal factor. At the average luminance of the stimulator the eyes were adapted to a low photopic level. The pupils were therefore partially dilated under these conditions, and this would theoretically increase the amount of distorted light due to spherical aberration, which can be an important consideration in IOL design. ${ }^{11}$ This blurring could produce a reduction in contrast, though we were unable to detect any correlation between pupil size and contrast sensitivity.

Visual acuity was measured on a conventional Snellen chart, viewed under photopic conditions (approximately 10 times the average luminance of the TV stimulus), and therefore the patient's pupils would be more constricted, reducing the influence of peripheral distortion. From this reasoning we would speculate that, if the contrast sensitivity experiment was performed under photopic conditions (for example, $100 \mathrm{Cd} \mathrm{m}^{-2}$ ), the observed differences in contrast sensitivity in pseudophakia may be attenuated or even disappear, and conversely, performed at reduced luminance (for example, $1 \mathrm{Cd} \mathrm{m}^{-2}$ ), the difference may be enhanced.

The delayed pattern reversal VEPs in $31 \%$ of the patients and reduced contrast sensitivity in $61 \%$ were probably due to poorer light transmission through the optic media, in particular the intact posterior capsule or the implant itself. Although the posterior capsule fibrosis did not appear to be clinically significant, it could still explain some of our findings by virtue of its position on or near the nodal point of the eye, since pathological evidence frequently shows fibrosis and membrane formation. ${ }^{12}$ However, our data do not preclude the possibility that some of these changes may have resulted from subtle alterations in retinal architecture resulting from mild postoperative cystoid macular oedema, which was not ophthalmoscopically apparent.

The reason for the difference in detection rate in the two VEP measures was most likely due to differences in the stimulus. The pattern reversal stimulus was very coarse, utilising very large checks at high contrast. Experiment has confirmed that this form of pattern modulation, in conjunction with checks of subtense $>20^{\prime}$, elicits VEPs which tend to respond to the luminance of the individual checks as well as the spatial contrast between them. This luminance modulation effect would tend to overcome to some degree any reduction in spatial contrast of the retinal image produced by opacification within the media. The onset-offset mode of stimulation, however, produces VEPs which have much purer components to spatial contrast, and when contrast sensitivity was investigated by this approach the detection rate of these latent contrast changes was much enhanced. The checksize used in this part of the experiment $\left(19^{\prime}\right.$ or $\left.25^{\prime}\right)$ determined contrast sensitivity in the 'mid-range' of the total contrast sensitivity function (which is approximately equal to the maxima found in the function when it is obtained psychophysically to sinusoidal grating, that is, at 2 cycles degree $\left.{ }^{-1}\right)$. The data therefore do not allow us to make predictions on whether overall contrast sensitivity was diminished, though the fact that all patients had a good standard of visual acuity suggests 
that sensitivity to small, high contrast elements near the resolution limit was unaffected.

In conclusion, our data show that it cannot be assumed that a good standard of central acuity measured postoperatively in pseudophakic patients, necessarily implies 'normal vision'. We would submit that the role of contrast sensitivity testing as a means of assessing the efficacy of an IOL implant, either by psychophysical methods or by using evoked potentials as we have done, has merit as a useful adjunct in the clinical management of these patients.

\section{References}

1 Stark WJ, Leske MC, Worthen DM, Murray GC. Trends in cataract surgery and intraocular lenses in the United States. Am J Ophthalmol 1983; 96: 304-10.

2 Wong D, McG Steele AD. A survey of intraocular lens implantation in the United Kingdom. Trans Ophthalmol Soc UK 1985; 104: $760-5$.

3 Jaffe NS, Clayman HM, Jaffe MS, Light MS. The results of extracapsular cataract extraction with a Shearing posterior chamber lens implant 39 to $\mathbf{4 0}$ months after surgery. Ophthalmic Surg 1982; 13: 47-9.
4 Ohroloff C, Dardenne MU, Konen C, Sherif A. Results of the first 1400 posterior chamber lens implantations after phacoemulsification. Klin Monatsbl Augenheilkd 1982; 181: 253-6.

5 Fagadau WR, Maumenee AE, Stark WJ, Datiles M. Posterior chamber intraocular lenses at the Wilmer Institute: a comparative analysis of complications and visual results. $\mathrm{BrJ}$ Ophthalmol 1984; 68: 13-8.

6 Hessburg PC, O'Malley ER. Hessburg anterior chamber intraocular lens results. Ophthalmic Surg 1985; 16: 237-41.

7 Arden GB. The importance contrast sensitivity in cases of visual disturbance. Br J Ophthalmol 1978; 62: 198-209.

8 Hess, RF, Woo G, White P. Contrast attenuation characteristics of iris clipped intraocular lens implants in situ. $\mathrm{BrJ}$ Ophthalmol 1985; 69: 129-35.

9 Howe, JW, Mitchell KW. The objective assessment of contrast sensitivity function by electrophysiological means. $\mathrm{Br} J$ Ophthalmol 1984; 68: 626-38.

10 Halliday AM. Evoked potentials in clinical testing. In: Halliday AM, ed. Clin Neurol Neurosurg Monogr. London: Churchill Livingstone, 1982: 3.

11 Wang GJ, Pomerantzeff $O$. Obtaining a high quality retinal image with a bi-convex intraocular lens. Am J Ophthalmol 1982; 94: 87-90.

12 McDonnell PJ, Stark WJ, Green WR. Posterior capsule opacification: a specular microscopic study. Ophthalmology (Rochester) 1984; 91: 853-6.

Accepted for publication 27 February 1986. 